\title{
REVIEWS.
}

\section{AN INTRODUCTION TO PSYCHOLOGICAL MEDICINE.}

By R. G. Gordon, N. G. Harris and J. R. Rees. Oxford University Press. 1936. Price $10 / 6$.

This book is written for the medical student. The writers quite rightly point out that the medical curriculum should include more rational education in psychological medicine. Too often in the past the only instruction which the student has received on the subject of the rôle of the mind in disease has been a series of lectures-not even always compulsory-on the major psychoses, together with a few visits to an "asylum " where he has been introduced to patients who either talked too much or not at all, and as to the mechanisms of whose illness he remained entirely in the dark.

The writers are of the opinion that the treatment of mental illness is a subject for post-graduate study, since it involves a knowledge of life's problems and of individual reactions which the medical student can scarcely be expected to possess. With this the authors are in entire agreement, and consequently no details of elaborate psychotherapeutic treatment have been given in this book, but the best medical educationists have always held that treatment is of lesser importance for the medical student. What he requires to know is the structure and function of the normal, how healthy processes go wrong, and hence what is the nature of disease. Given this knowledge diagnosis will be relatively easy and appropriate treatment not hard to apply. This textbook seems to meet the needs of the medical student.

\section{RESEARCH ON THE LOW POTENCIES Of HOMEOPATHY.}

By W. E. Boyd, M.A., M.D., Lond.

1936. Wm. Heinemann Ltd. Price $2 / 6$.

In this little monograph the author admits that the experimenter in homeopathy is more likely to be satisfied if he can be shown that a drug in a stage of homeopathic preparation is capable of a definite physical activity. The book purports to give an account of the spectral examination of certain " low potency" homeopathic preparations, and to show that definite physical or chemical properties are present in homeopathic preparations of widely different origins.

So far as this stated purpose is concerned, Dr. Boyd appears to us to achieve it in this little volume. Those readers who wish to be acquainted with the essential facts in regard to the research carried out on these lines on behalf of the Beit Research Committee of the British Homeopathic Association will find them stated clearly enough in this publication.

\section{THE RELIEF OF PAIN: A Handbook of Modern Analgesia.}

By Harold Balme, M.D., F.R.C.S., D.P.H. 1936 . J. \& A. Churchill, Ltd. pp.392. Price 12/6.

Among the many questions which ever have vexed the mind of Man the problem of pain is, perhaps, the most inscrutable; it is certainly universal in its appeal to thinkers of every type, philosophers, theologians, scientists. Of medicine it may be said indeed to be the raison d'être.

There are few medical writings in which reference is not made, in greater or less degree, to the relief of suffering, but we know of none in which this subject has been treated at once so exhaustively and so succinctly as in this pleasant and readable book, on which we offer to the author our warmest congratulations. The keynote of this work is expressed at the beginning of Chapter VI :- " The call of pain presents a double appeal to every conscientious physician. It is at once a call to investigation and a call for relief, and neither can be truly obeyed without the fullest recognition of, and response to, 
the other." This thesis is well illustrated in the arrangement of the various chapters, in which we see an orderly and logical sequence of thought.

Part I deals with the problem of pain in its various aspects, both physical and psychological; it includes an excellent résumé of the anatomy and physiology of the appropriate portions of the nervous system, as well as a summary of the different hypotheses which have been advanced as to the actual nature of pain, whether organic or psychogenic. The classification of painful sensations given in Chapter $\mathrm{V}$ is eminently practical. This and the following chapter on the investigation of pain we would commend especially to the student as a preliminary lesson which he might well commit to memory.

Parts II and III form the bulk of the work, in which the investigation and treatment of pain are considered in detall, Part II being devoted to general and systemic pain, Part III to regional pain. Emphasis is laid throughout on ætiological considerations, and the reader is left with little excuse for treating symptoms in ignorance of their cause, an unforgivable fault which the author is at pains to condemn.

Part IV deals with the therapeutics of analgesia. The fundamental principles which underlie treatment are briefly but adequately summarised. The two special chapters by Dr. Matthew B. Ray on details of hydrotherapy, movements, massage, and electro-therapy form a valuable addition to the author's own work and render the whole volume all the more complete. In the final chapter is given a list of all the most effective anaigesic drugs, including many of the modern proprietary remedies the value of which has been shown by experience. The usefulness of this appendix can hardly be overestimated.

A good list of references is supplied at the end of each chapter, and last but not least comes an excellent general index.
In writing this book, the character of $\frac{\Phi}{2}$ which is unique, and the merit, in our $C$ estimation, outstanding, Dr. Balme has $\underset{\vec{D}}{\overrightarrow{0}}$ filled a very definite gap in medical litera- $-\overrightarrow{0}$ ture, and we strongly recommend it to our 들 readers as a practical and useful volume, $\frac{\bar{\omega}}{\bar{D}}$ of moderate price and well worth the pur- $\stackrel{\mathbb{Q}}{\Omega}$ chase. Three things especially have impressed us :-In the first place, the book $\overrightarrow{0}$ is inclusive-of information which a prac- $\vec{A}$ titioner is likely to need there is little indeed that he will not find in these pages. In the second place, it is detailed, and will, 3 therefore, appeal to the practical man, the $\vec{N}$ technique of treatment being sufficiently $\vec{\omega}$ adumbrated and not, as in so many text- N books, left largely to the reader's imagination. Lastly, the style is attractive, ando indicates the mind of a true philosophero

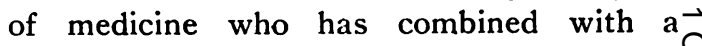
scientific knowledge of his subject that sympathetic insight into the psychology of men and women which goes far to make the ideal physician.

\section{EXAMINING BOARD IN ENGLAND} BY TIE

ROYAL COLLEGE OF PHYSICIANS OF LONDON AND THE

ROYAL COLLEGE OF SURGEONS OF ENGLAND.

\section{DIPLOMA IN ANFSTHETICS.}

Notice is hereby given that the next Examination for the Diploma in Anæsthetics will commence on FRIDAY, November 13th 1936.

Candidates who have complied with the necessary requirements, and who desire to present themselves for the above Examination must apply in writing to the Secretary, Examination Hall, 8-II, Queen Square, London, W.C.I, at least twenty-one days before the date of the Examination.

HORACE H. REW, Secretary. 